Supplementary Materials for

\title{
Thermoresponsive Structure and Dye Encapsulation of Micelles Comprising Bolaamphiphilic Quercetin Polyglycoside
}

\author{
Mahmuda Nargis, Abu Bin Ihsan, and Yasuhito Koyama* \\ Department of Pharmaceutical Engineering, Faculty of Engineering \\ Toyama Prefectural University, 5180 Kurokawa, Imizu, Toyama 939-0398, Japan \\ E-mail: ykoyama@pu-toyama.ac.jp
}

Contents

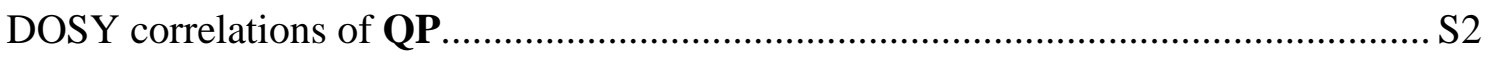

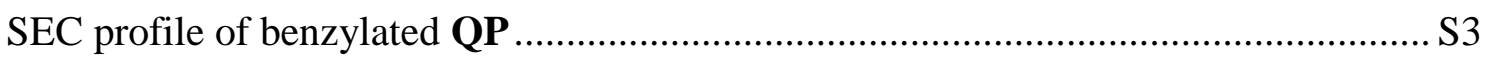

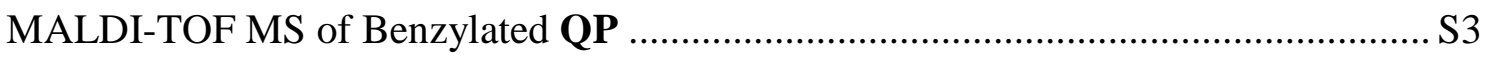

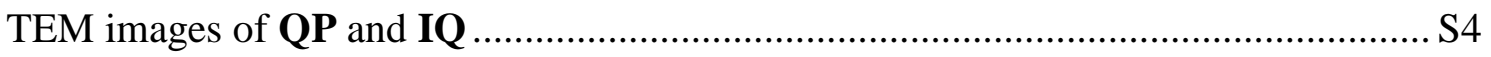

UV-vis spectra of QP, IQ, and Que in $\mathrm{pH} 7.0$ aqueous media................................... S5

DLS profiles of QP, IQ, and Que at various temperatures........................................ 6

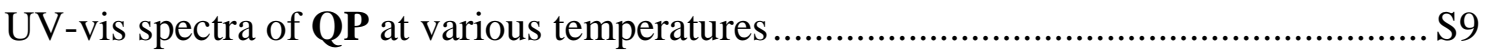

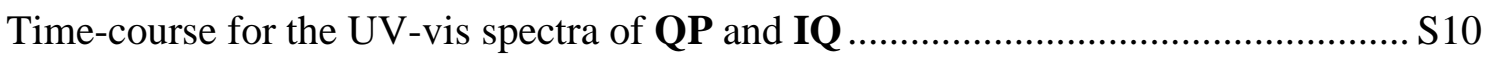

DLS profiles of QP before and after encapsulation of Nile red ............................... S11 


\section{DOSY correlations of QP}

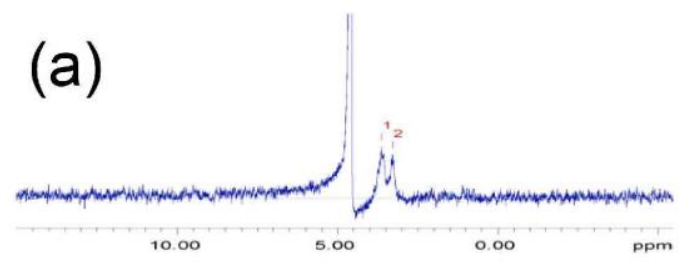

(b)
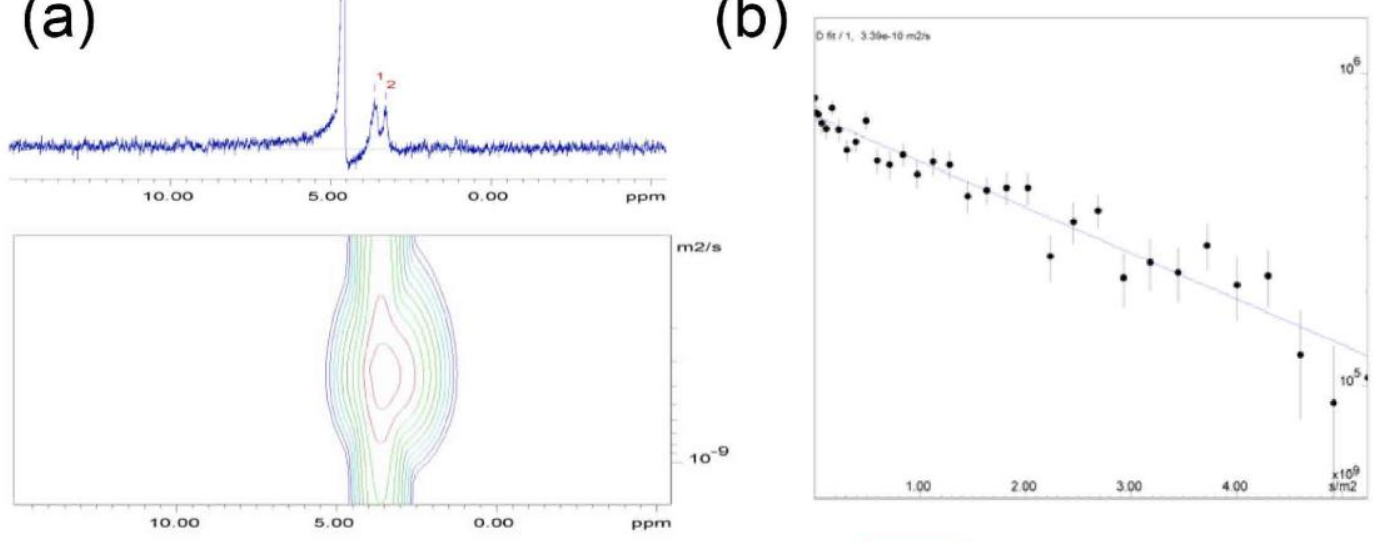

(c)

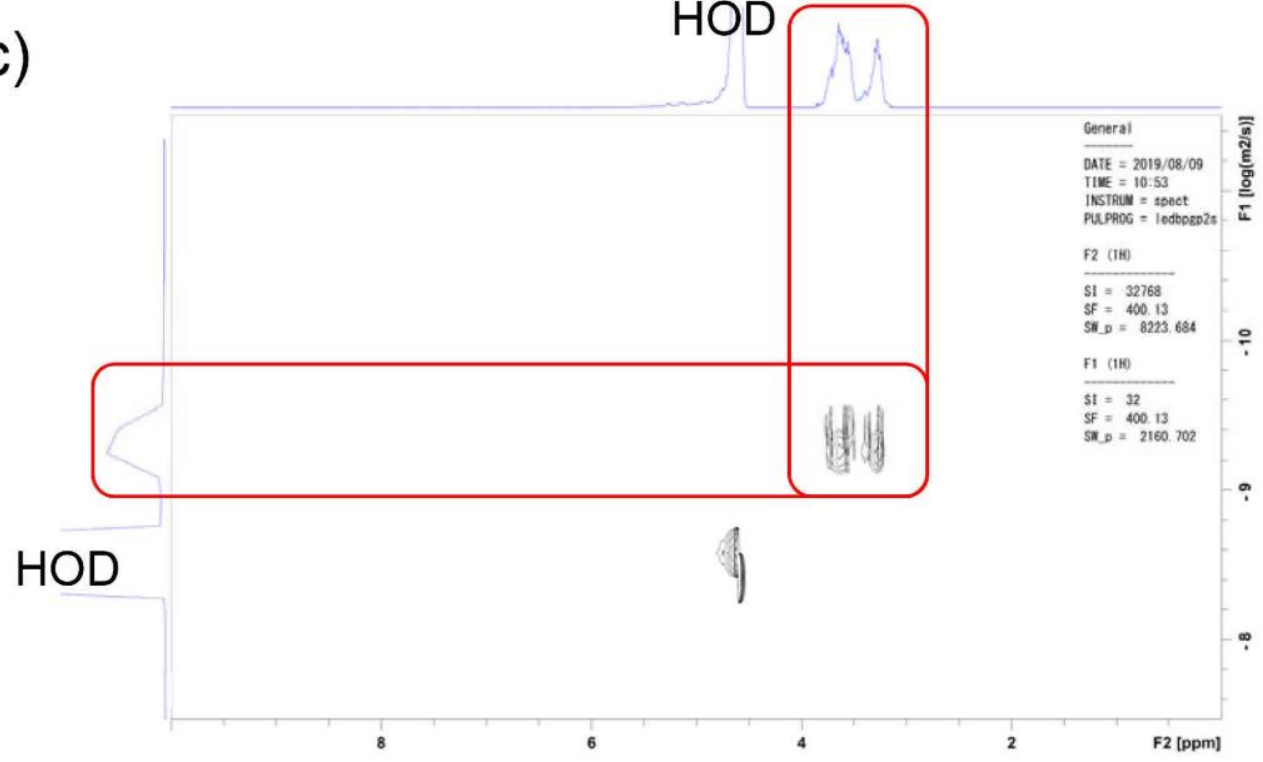

Figure S1. (a) DOSY correlations of QP below CMC (500 MHz, $\left.\mathrm{D}_{2} \mathrm{O}, 298 \mathrm{~K}\right)$ analyzed by using a Dynamics Center software, (b) the attenuation curve, and (c) the diffusion dimension obtained by the SimFit method. 


\section{SEC profile of benzylated QP.}

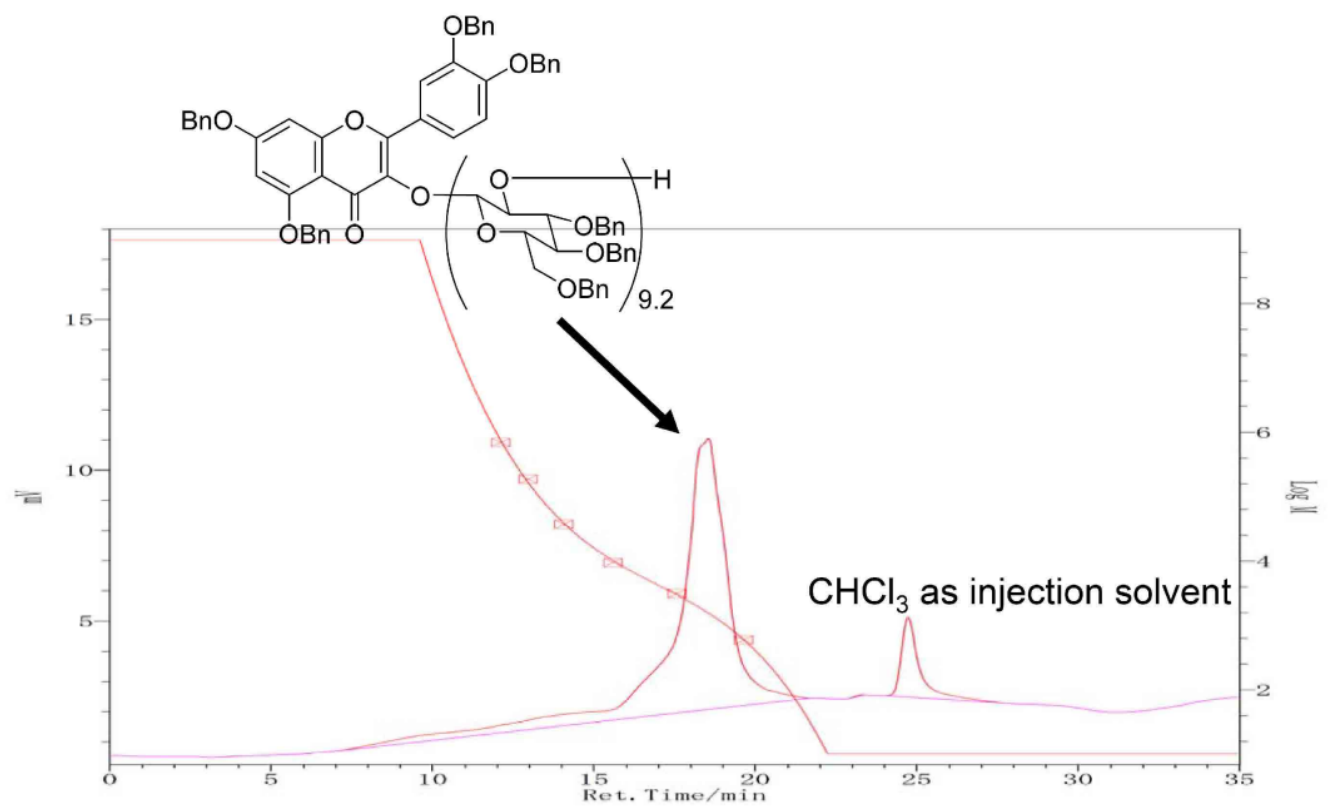

Figure S2. SEC profile of benzylated QP as the precursor of QP (eluent: THF). $M_{\mathrm{n}} 3,600, M_{\mathrm{w}} / M_{\mathrm{n}} 1.2$ (on the basis of polystyrene standards).

\section{MALDI-TOF MS of Benzylated QP.}

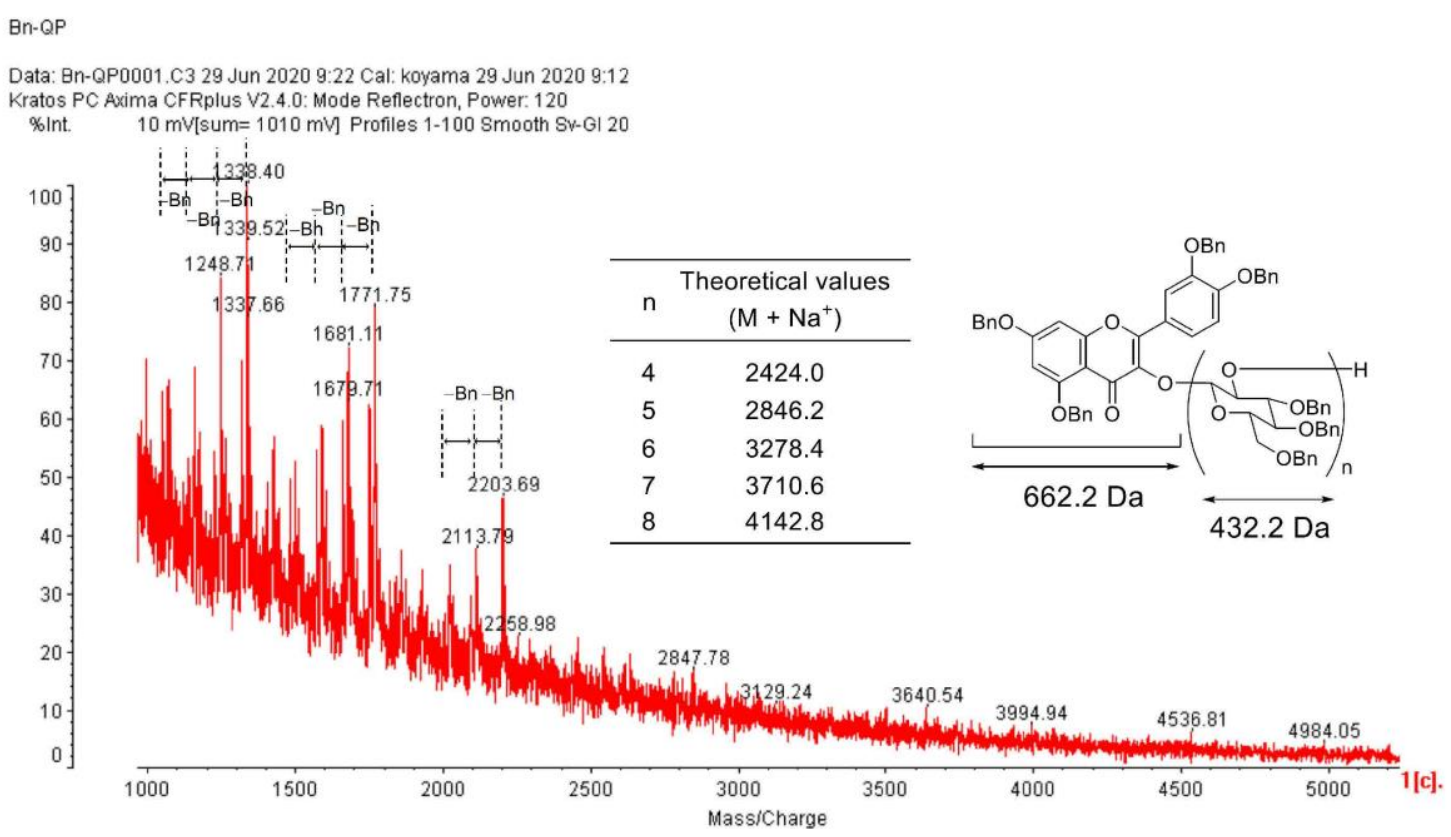

Figure S3. MALDI-TOF MS of benzylated QP (matrix: CHC $\alpha$ ). 


\section{TEM images of QP and IQ.}

(a)

(i)

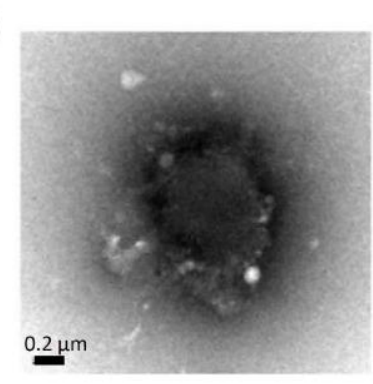

(ii)

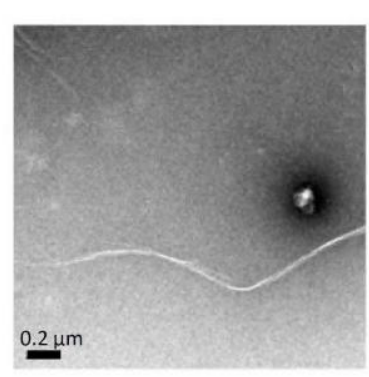

(iii)

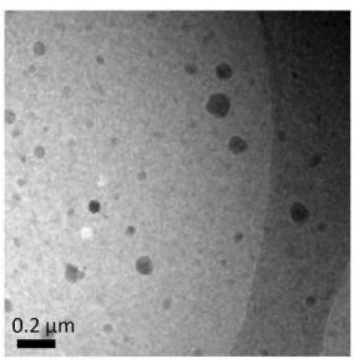

(b)

(i)

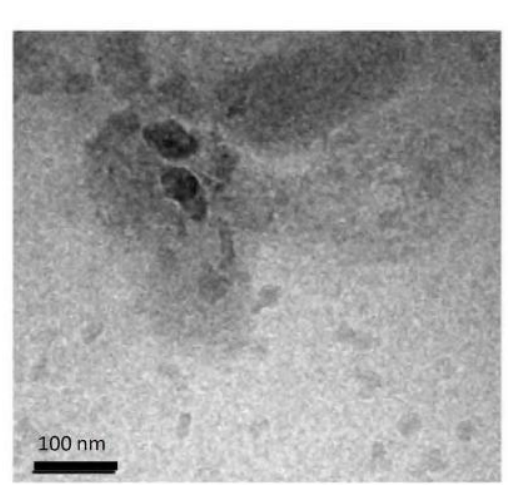

(ii)

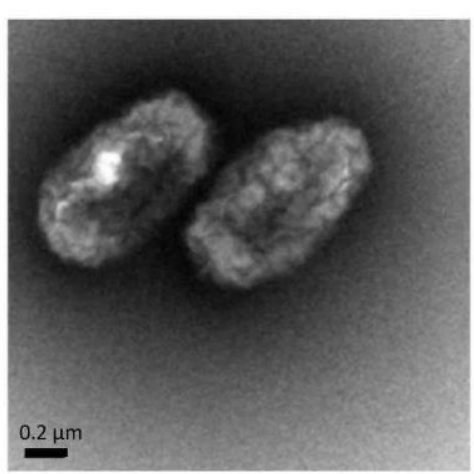

Figure S4. TEM observations of micelles in $\mathrm{pH} 7$ aqueous media of (a) QP $(564 \mu \mathrm{M})$ in the presence of phosphotungstic acid as a negative stain; (i) spherical micelles and (ii) giant ribbon-like micelles generated by bundling for precooled sample at $4{ }^{\circ} \mathrm{C}$. (iii) Cryo-TEM image of preheated sample at 80 ${ }^{\circ} \mathrm{C}$ : The sample solution of QP was preheated at $80^{\circ} \mathrm{C}$ in an incubator, which was immediately applied on the TEM grid. The remaining solution on the grid was removed by contacting with a filter paper. The obtained grid was then immersed into liquid ethane, which was used for the cryo-TEM measurements. (b) TEM observations of micelles comprising IQ $(40.0 \mu \mathrm{M})$ in $\mathrm{pH} 7$ aqueous media: (i) cryo-TEM image and (ii) TEM image in the presence of phosphotungstic acid as a negative stain. The sample for the cryo-TEM was treated with liquid ethane before the measurement. 
UV-vis spectra of QP, IQ, and Que in pH 7.0 aqueous media.
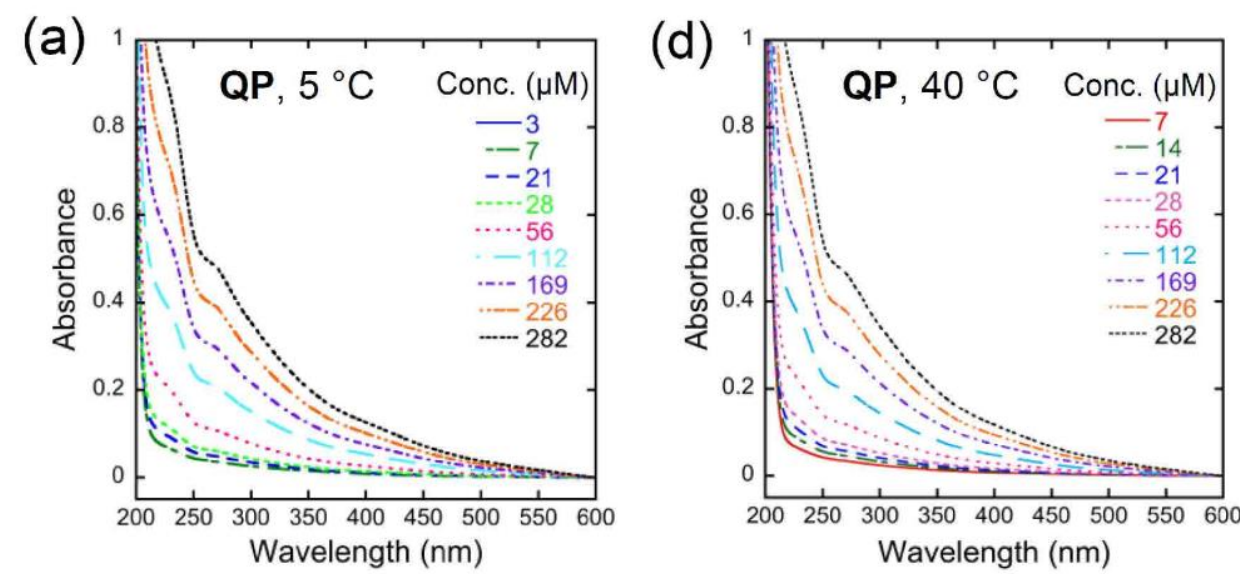

(b)

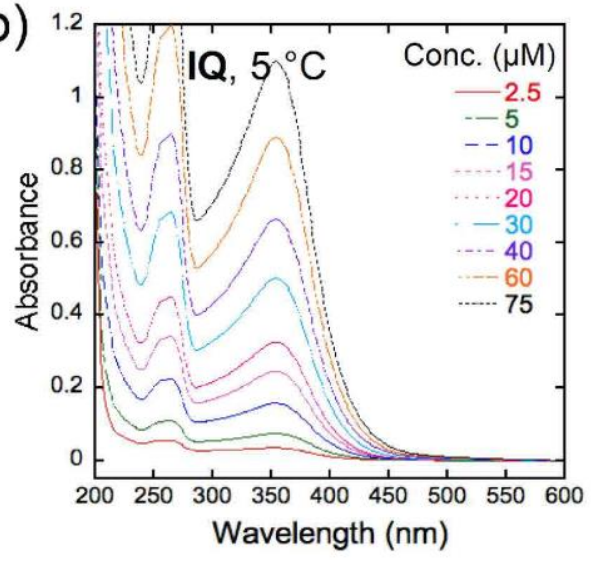

(c)

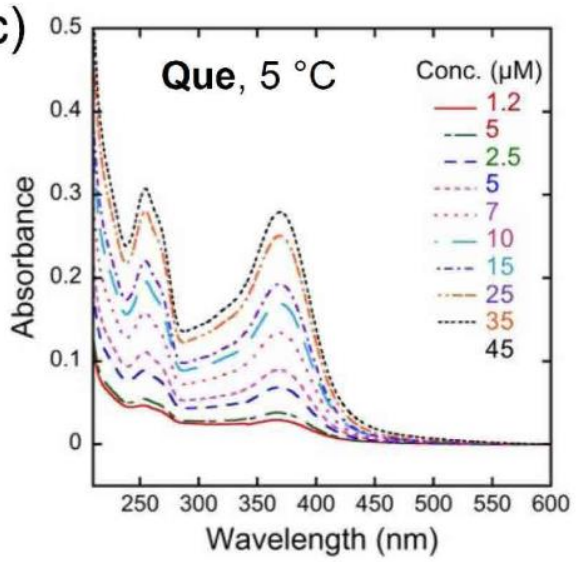

(e)

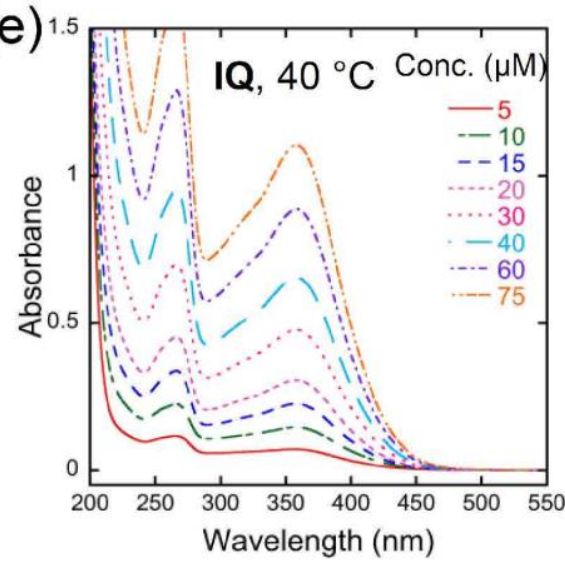

(f)

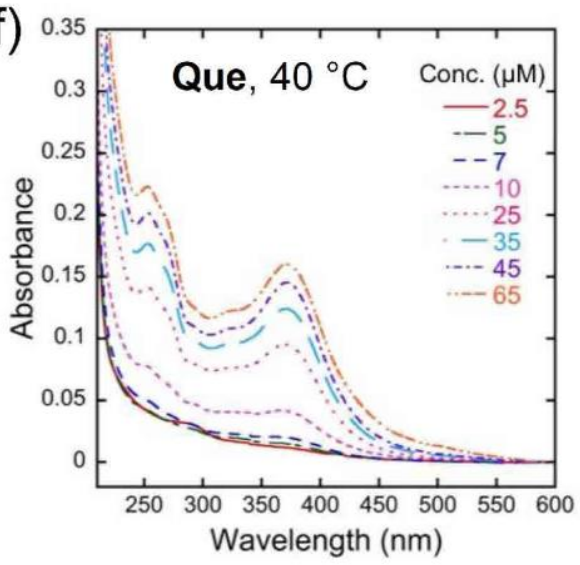

Figure S5. UV-vis spectra of (a) $\mathbf{Q P}$ at $5{ }^{\circ} \mathrm{C}$, (b) IQ at $5{ }^{\circ} \mathrm{C}$, (c) Que at $5{ }^{\circ} \mathrm{C}$, (d) $\mathbf{Q P}$ at $40{ }^{\circ} \mathrm{C}$, (e) IQ at $40^{\circ} \mathrm{C}$, and (f) Que at $40^{\circ} \mathrm{C}$ in $\mathrm{pH} 7.0$ aqueous media. 


\section{DLS profiles in pH 7 aqueous media at various temperatures.}

(a)

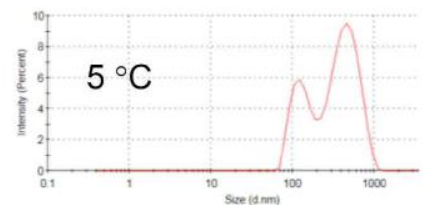

PDI: 0.42 , Dh: $456 \mathrm{~nm}(66.4 \%)$ and $128 \mathrm{~nm}(29.3 \%)$

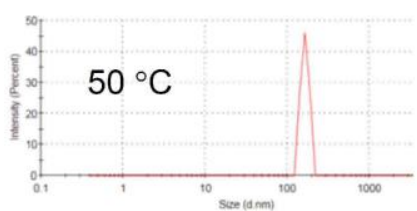

PDI: 1.0, Dh: 165 nm (100\%)

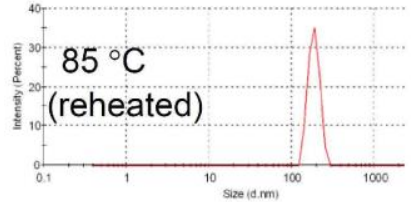

PDI: 0.53, Dh: 188 nm (100\%)

(b)

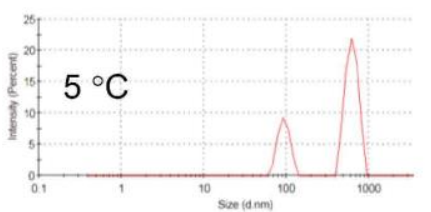

PDI: 1.0, Dh: $627 \mathrm{~nm}(72.2 \%)$ and $94 \mathrm{~nm}(27.8 \%)$

(c)

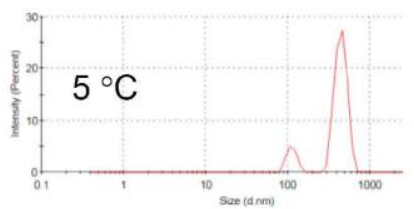

PDI: 0.97, Dh: $447 \mathrm{~nm}(86.6 \%)$ and $112 \mathrm{~nm}(13.4 \%)$.

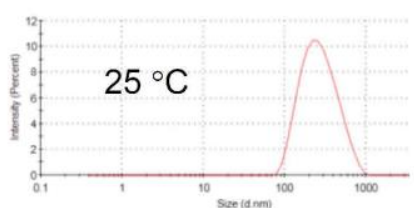

PDI: 0.51, Dh: 300 nm (100\%)

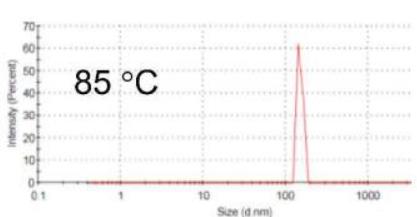

PDI: 0.82, Dh: $150 \mathrm{~nm}(100 \%)$

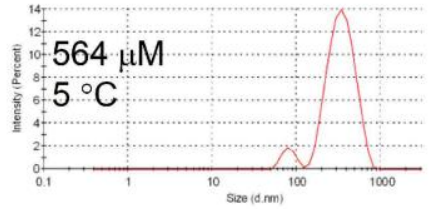

PDI: 0.34, Dh: 358 nm (89.8\%) and $82 \mathrm{~nm}(6.3 \%)$

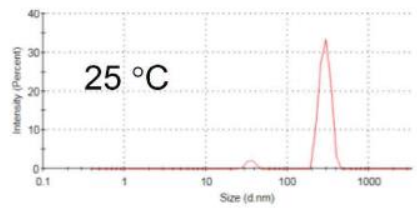

PDI: 0.95, Dh: 475 nm (94.9\%) and $35 \mathrm{~nm}(5.1 \%)$.

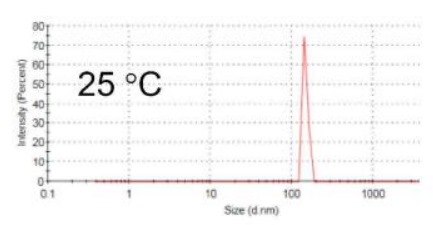

PDI: 1.0, Dh: 188 nm (100\%)

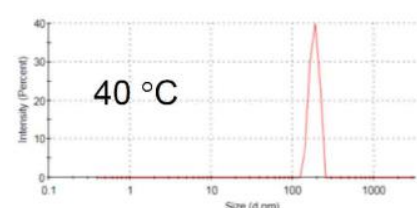

PDI: 1.0, Dh: 179 nm (100\%)

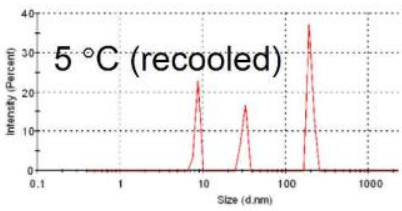

PDI: 1.0, Dh: $198 \mathrm{~nm}(50.4 \%)$, $31 \mathrm{~nm}(23.5 \%)$, and $8 \mathrm{~nm}(26.1 \%)$

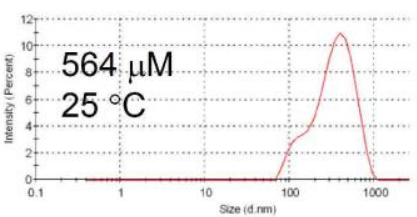

PDI: 0.45, Dh: 368 nm (100\%)
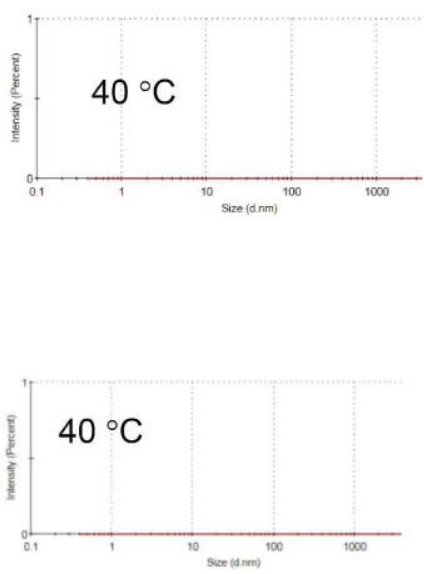

Figure S6. DLS profiles at various temperatures of a) QP $(56.0 \mu \mathrm{M})$, b) IQ $(25.0 \mu \mathrm{M})$, and c) Que $(20.0 \mu \mathrm{M})$ in $\mathrm{pH} 7.0$ aqueous media. 


\section{DLS profiles in pH 4 aqueous media at various temperatures.}

(a)

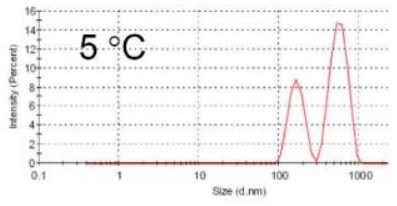

PDI: 0.70, Dh: $574 \mathrm{~nm}(65.9 \%)$ and $169 \mathrm{~nm}(34.1 \%)$

(b)

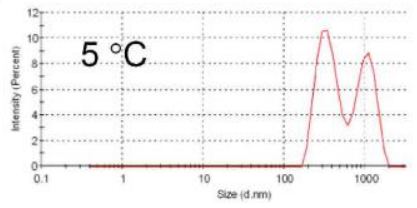

PDI: $0.90, \mathrm{Dh}: 356 \mathrm{~nm}(56.4 \%)$ and $1049 \mathrm{~nm}(43 \%)$

(c)

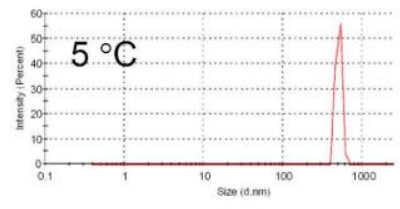

PDI: 1.0, Dh: 506 nm (100\%)

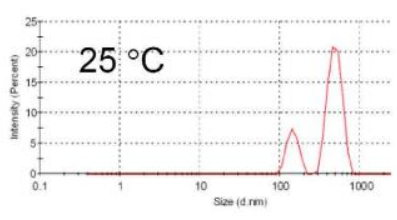

PDI: 0.70, Dh: $492 \mathrm{~nm}(77.9 \%)$ and $146 \mathrm{~nm}(22.1 \%)$

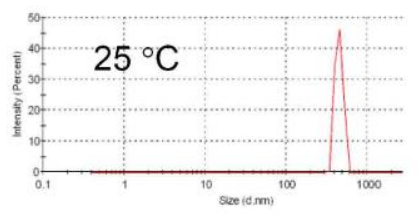

PDI: 0.70, Dh: $450 \mathrm{~nm}(100 \%)$
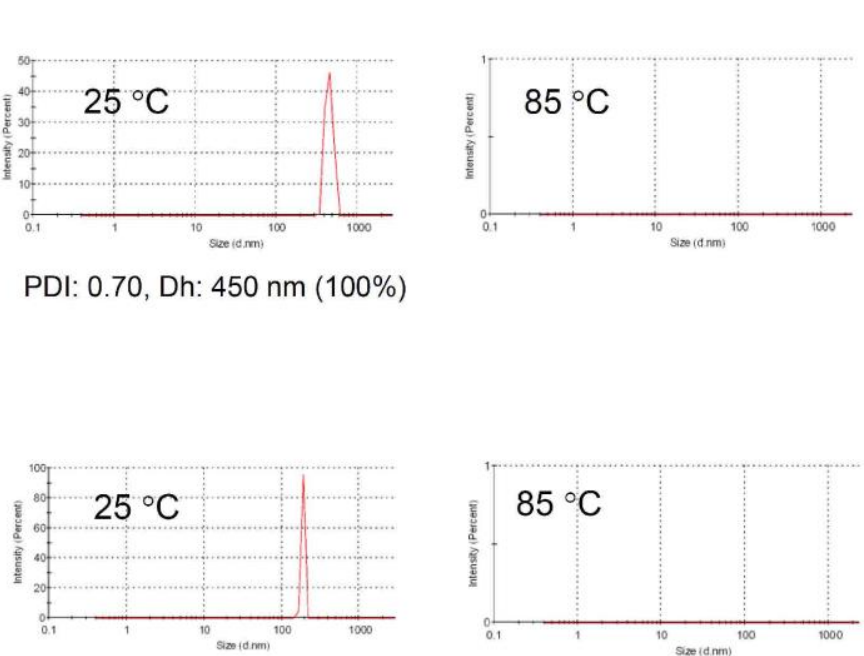

PDI: 1.0, Dh: 189 nm (100\%)

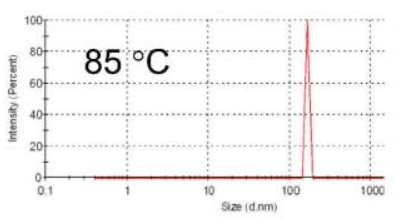

PDI: 0.97, Dh: 164 nm (100\%)
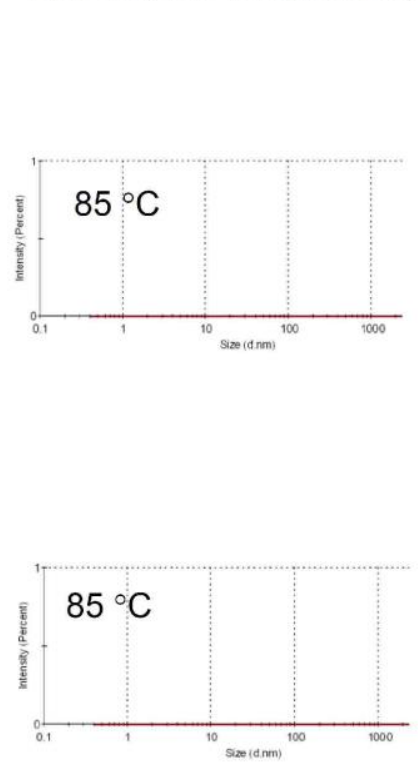

Figure S7. DLS profiles at various temperatures of a) QP $(100.0 \mu \mathrm{M})$, b) IQ $(25.0 \mu \mathrm{M})$, and c) Que $(20.0 \mu \mathrm{M})$ in $\mathrm{pH} 4.0$ aqueous media. 


\section{DLS profiles in pH 10 aqueous media at various temperatures.}

(a)

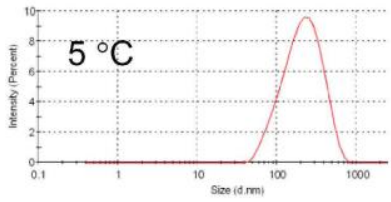

PDI: 0.37, Dh: 273 nm (100\%)

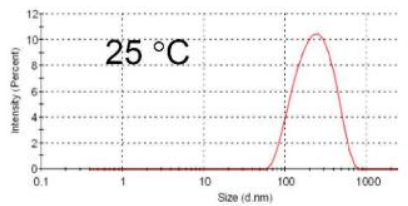

PDI: 0.37, Dh: 253 nm (100\%)

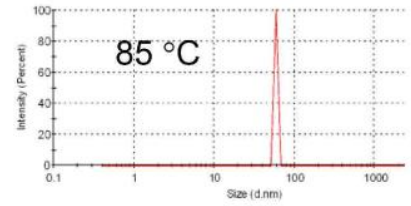

PDI: 0.37, Dh: 59 nm (100\%)

(b)

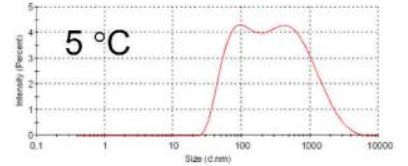

PDI: 0.82, Dh: 744 nm (58.4\%) and $103 \mathrm{~nm}(41.6 \%)$

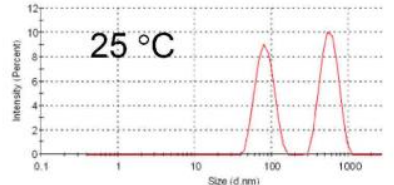

PDI: 0.87, Dh: 576 nm (53.3\%) and $83 \mathrm{~nm}(46.7 \%)$

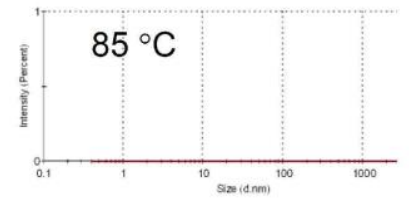

Figure S8. DLS profiles at various temperatures of a) QP $(56.0 \mu \mathrm{M})$ and b) IQ $(25.0 \mu \mathrm{M})$ in $\mathrm{pH} 10.0$ aqueous media.

Table S1. pH- and temperature-dependent hydrodynamic diameters of the micelles.

\begin{tabular}{|c|c|c|c|c|}
\hline & $\mathrm{pH}$ & $5^{\circ} \mathrm{C}$ & $25^{\circ} \mathrm{C}$ & $85^{\circ} \mathrm{C}$ \\
\hline \multirow{3}{*}{ QP } & 4.0 & $\begin{array}{l}574 \pm 133 \mathrm{~nm}, \\
169 \pm 36 \mathrm{~nm}\end{array}$ & $\begin{array}{l}492 \pm 95 \mathrm{~nm} \\
146 \pm 23 \mathrm{~nm}\end{array}$ & $164 \pm 0 \mathrm{~nm}$ \\
\hline & 7.0 & $\begin{array}{l}456 \pm 178 \mathrm{~nm} \\
128 \pm 33 \mathrm{~nm}\end{array}$ & $300 \pm 108 \mathrm{~nm}$ & $150 \pm 11 \mathrm{~nm}$ \\
\hline & 10.0 & $273 \pm 124 \mathrm{~nm}$ & $253 \pm 124 \mathrm{~nm}$ & $59 \pm 0 \mathrm{~nm}$ \\
\hline \multirow{3}{*}{ IQ } & 4.0 & $\begin{array}{l}356 \pm 108 \mathrm{~nm}, \\
1049 \pm 275 \mathrm{~nm}\end{array}$ & $450 \pm 48 \mathrm{~nm}$ & Not detected \\
\hline & 7.0 & $\begin{array}{l}627 \pm 106 \mathrm{~nm} \\
94 \pm 15 \mathrm{~nm}\end{array}$ & $475 \pm 102 \mathrm{~nm}$ & Not detected \\
\hline & 10.0 & $\begin{array}{l}744 \pm 163 \mathrm{~nm} \\
103 \pm 46 \mathrm{~nm}\end{array}$ & $\begin{array}{l}576 \pm 141 \mathrm{~nm}, \\
83 \pm 21 \mathrm{~nm}\end{array}$ & Not detected \\
\hline \multirow{3}{*}{ Que } & 4.0 & $506 \pm 42 \mathrm{~nm}$ & $189 \pm 5 \mathrm{~nm}$ & Not detected \\
\hline & 7.0 & $\begin{array}{l}447 \pm 74 \mathrm{~nm}, \\
112 \pm 15 \mathrm{~nm}\end{array}$ & $188 \pm 8 \mathrm{~nm}$ & Not detected \\
\hline & 10.0 & Not detected & Not detected & Not detected \\
\hline
\end{tabular}




\section{UV-vis spectra of QP at various temperatures.}
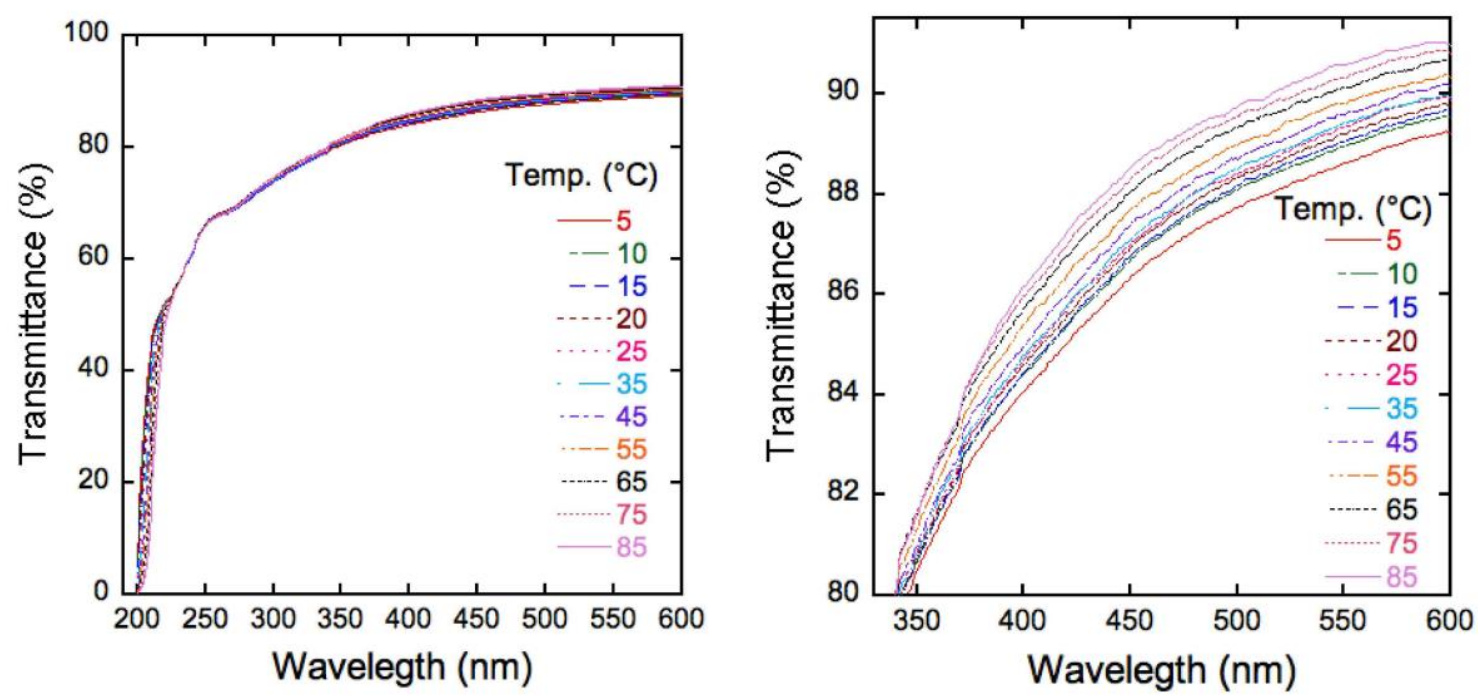

Figure S9. UV-vis spectra of $\mathbf{Q P}(56.0 \mu \mathrm{M})$ in $\mathrm{pH} 7.0$ aqueous media upon heating from $5{ }^{\circ} \mathrm{C}$ to 85 ${ }^{\circ} \mathrm{C}$.
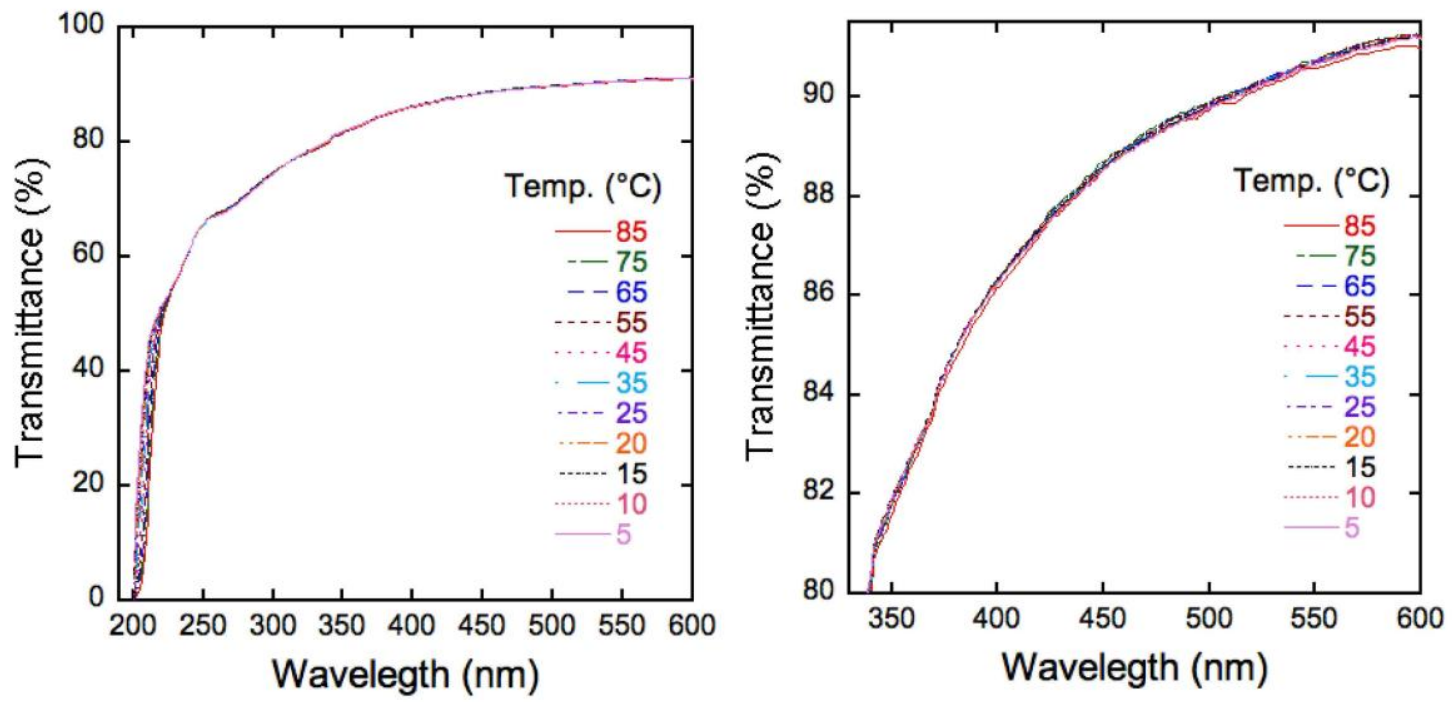

Figure S10. UV-vis spectra of $\mathbf{Q P}(56.0 \mu \mathrm{M})$ in $\mathrm{pH} 7.0$ aqueous media upon cooling from $85{ }^{\circ} \mathrm{C}$ to 5 ${ }^{\circ} \mathrm{C}$. 


\section{Time-course for the UV-vis spectra of QP and IQ.}

(a)

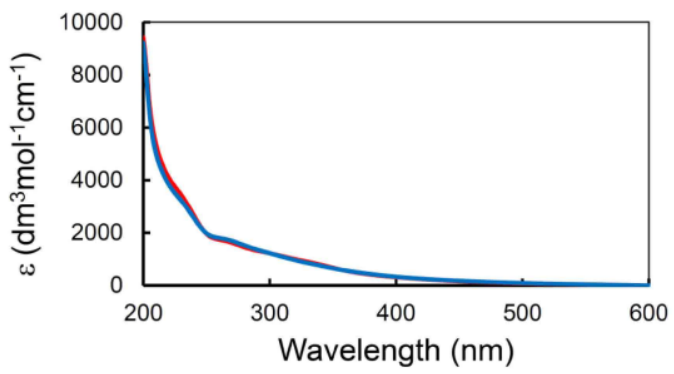

(b)

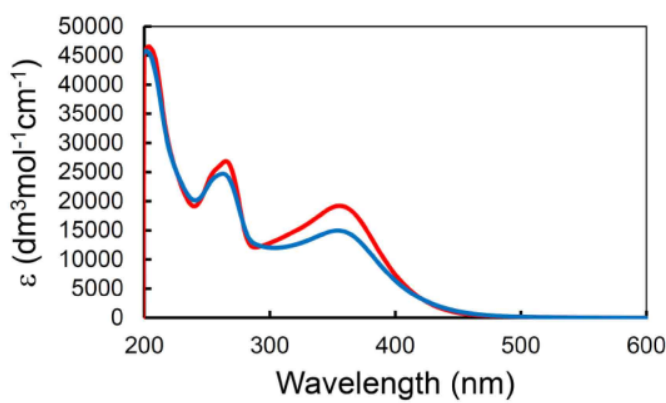

(c)

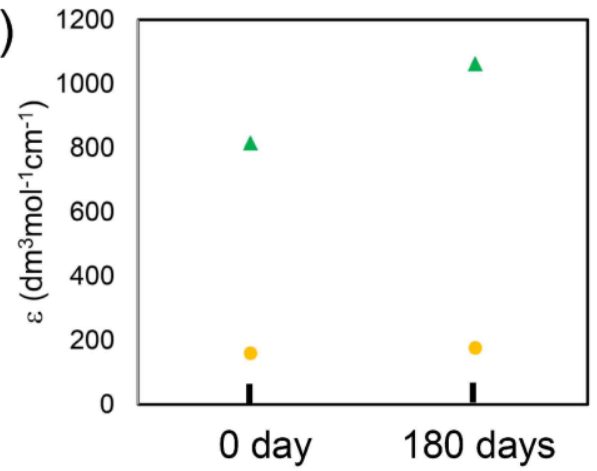

Figure S11. UV-vis spectra of (a) QP at freshly prepared (red) and after $180 \mathrm{~d}$ (blue) and (b) IQ at freshly prepared (red) and after $180 \mathrm{~d}$ (blue), and (c) time-dependence of absorbance at $450 \mathrm{~nm}$ of QP (orange circle) and IQ (green triangle). 


\section{DLS profiles of QP before and after encapsulation of Nile red.}
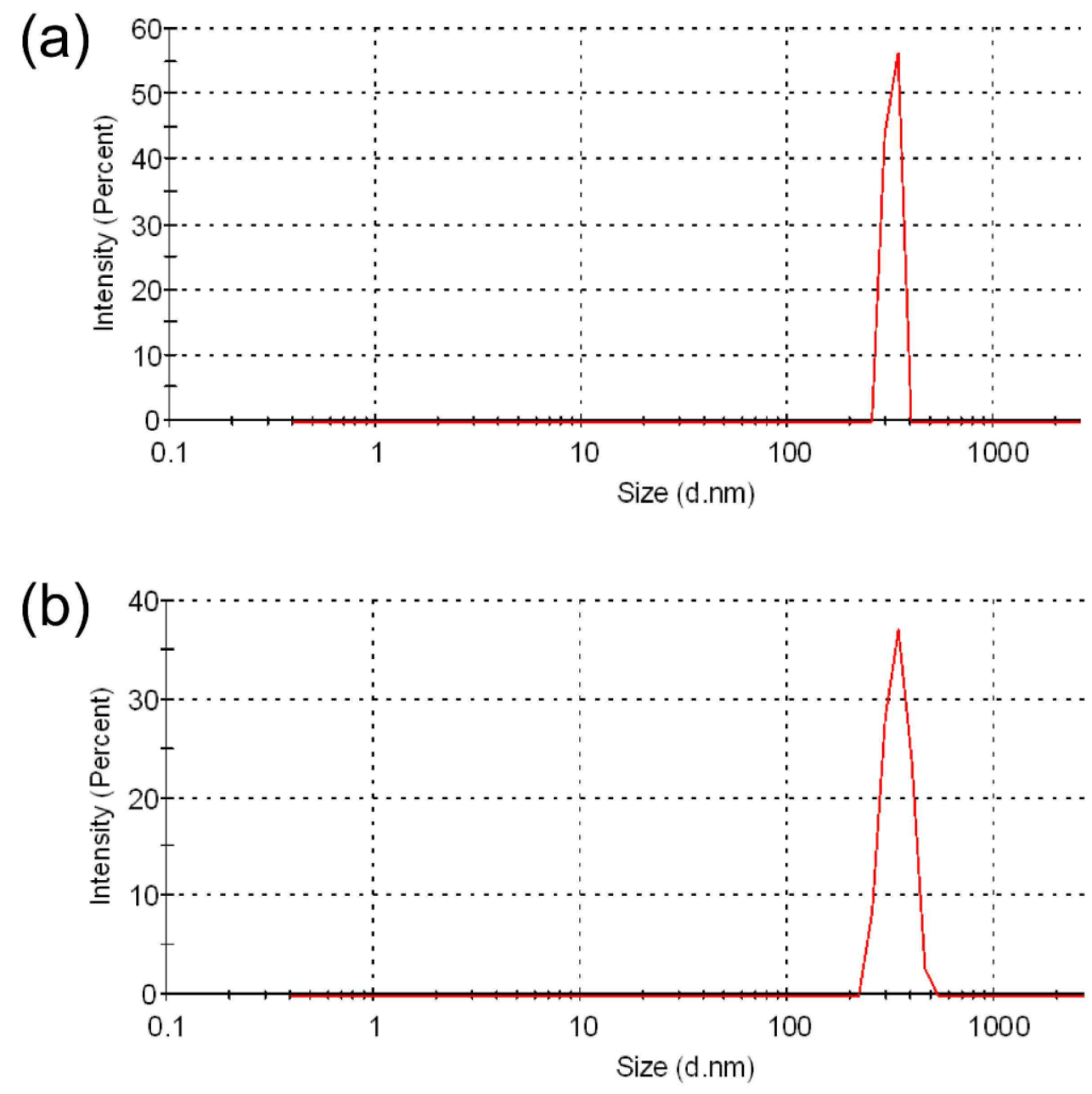

Figure S12. DLS profiles of Que (140.0 $\mu \mathrm{M})$ (a) before and (b) after encapsulation of Nile red in $\mathrm{pH}$ 7.0 aqueous media at $25{ }^{\circ} \mathrm{C}$. PDI: (a) 0.81 and (b) 0.72, Dh: (a) $321 \mathrm{~nm}(100 \%)$ and (b) $337 \mathrm{~nm}$ $(100 \%)$. 